\title{
Co-evolution of continental weathering and marine redox state in the Cryogenian interglaciation: a case study from South China
}

\author{
GUANG-YI WEI ${ }^{1 *}$, HONG-FEI LING ${ }^{1}$ \\ ${ }^{1}$ School of Earth Sciences and Engineering, Nanjing \\ University, 163 Xianlin Avenue, Nanjing 210023, China
}

There has been extensive debate about the co-evolution of Earth's surface environment and biological radiation in the late Neoproterozoic. Further, the studies of triggers for marine redox changes in the deep time are sparse. In order to better constrain the links between continental weathering and shelf-marginal seawater redox state in this critical interval, we conduct a case study of the Cryogenian interglacial Datangpo Formation, South China. We present first high-resolution lithium isotope data of the siliciclastic strata in South China to track the secular changes in chemical weathering intensity during the Cryogenian interglacial period, given that $\mathrm{Li}$ isotopes of modern riverine detrital loads are closely linked to chemical weathering regimes (e.g., Dellinger et al., 2014, 2017). A dramatically negative $\mathrm{Li}$ isotope excursion is oberved in the basal Datangpo Formation, South China, suggesting a significantly increase in chemical weathering in the aftermath of the Sturtian glaciation. Combined with iron speciation and trace elements, new lithium isotope data imply that temporal changes in marine redox states in the continent shelf area are most likely driven by continental chemical weathering evolution. The expansion of euxinic seawater in the early deglacial period coincides with the dramatic increase in chemical weathering intensity that may promote the inputs of nutrients and sulfates to the regional seawater. By contrast, the waning of marine euxinia may have been induced by sluggish microbial sulfate reduction due to the lack of organic matter and sulfate following the decline in continental chemical weathering.

Reference

[1] Dellinger M. et al. Earth and Planetary Science Letters

(2014) 401: 587-590.

[2] Dellinger M. et al. Geology (2017) 45: 411-414. 